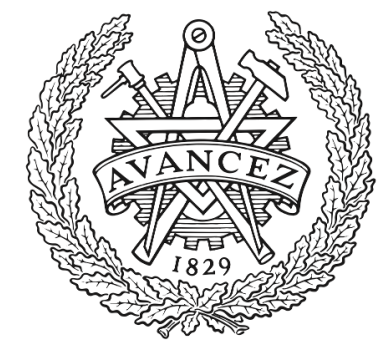

CHALMERS

UNIVERSITY OF TECHNOLOGY

\title{
Potentials and challenges for user-generated video content in public libraries
}

Downloaded from: https://research.chalmers.se, 2023-04-26 13:57 UTC

Citation for the original published paper (version of record):

Yoo, D., Novais, N., Klokmose, C. et al (2019). Potentials and challenges for user-generated video content in public libraries. Conference on Human Factors in Computing Systems - Proceedings. http://dx.doi.org/10.1145/3290607.3312842

N.B. When citing this work, cite the original published paper. 


\begin{tabular}{|l|l|l|}
\hline Method & Location & Participants \\
\hline $\begin{array}{l}\text { Semi-structured } \\
\text { focus group } \\
\text { interview }\end{array}$ & PL1 & $\begin{array}{l}\text { Three library staff including } \\
\text { Digital Editor (D1), Head of } \\
\text { Communications (D2), } \\
\text { Project Development (D3) }\end{array}$ \\
\hline $\begin{array}{l}\text { Semi-structured } \\
\text { focus group } \\
\text { interview via Skype }\end{array}$ & PL2 & Three librarians (L1, L2, L3) \\
\hline $\begin{array}{l}\text { Semi-structured } \\
\text { individual interview } \\
\text { using design } \\
\text { scenarios }\end{array}$ & PL1 & Digital Editor (D1) \\
\hline
\end{tabular}

Figure 1: Overview of the video study from a main library in Denmark and a branch library in Sweden. The design scenarios are presented in Figure 2, 3, and 4.

\section{Potentials and Challenges for User-generated Video Content in Public Libraries}

\author{
Daisy Yoo $\dagger$ \\ Nathalia Novais $\dagger$ \\ Clemens Klokmose $\dagger$ \\ Peter Dalsgaard $\dagger$ \\ University of Aarhus $\dagger$ \\ Aarhus, Denmark \\ dyoo@cc.au.dklevae@cc.au.dk
}

\begin{abstract}
The role of libraries are rapidly shifting, in large part as a consequence of digitization. In addition to providing access to collections of books and other physical media, public libraries today are embracing a new role of becoming urban hubs, in which a wide range of activities take place. In these activities, local knowledge is developed, exchanged, and disseminated. However, there are still very few digital services that support this new role. Here, we explore how to develop digital services for supporting and leveraging user-generated video content in library activities. Based on interviews and design scenarios as probes, we describe the potentials and challenges for designing such services, as seen from the perspective of library staff. Our insights will inform the design of a new digital service for publics to participate in collaborative production of videos to document, exchange, and disseminate local knowledge generated in library activities.
\end{abstract}

Permission to make digital or hard copies of part or all of this work for personal or classroom use is granted without fee provided that copies are not made or distributed for profit or commercial advantage and that copies bear this notice and the full citation on the first page. Copyrights for third-party components of this work must be honored. For all other uses, contact the owner/author(s).

CHI'19 Extended Abstracts, May 4-9, 2019, Glasgow, Scotland UK

() 2019 Copyright held by the owner/author(s).

ACM ISBN 978-1-4503-5971-9/19/05.

https://doi.org/10.1145/3290607.3312842 


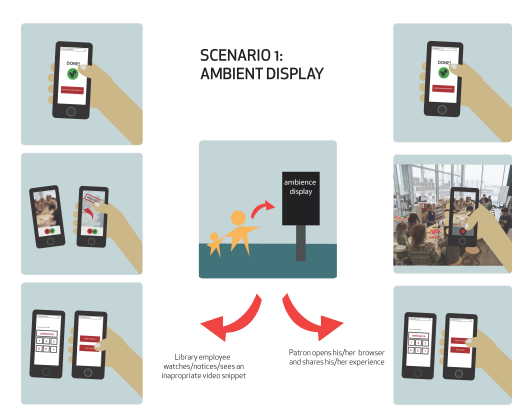

Figure 2: Scenario 1 - Patrons can share a video snippet of their experience via large public displays in the library. The video is intended to inspire other users to participate and share new snippets. If a video is submitted, library staff can accept or reject it by swiping left to delete, or right to show on the public display.

\section{KEYWORDS}

user-generated video; public library; $\mathrm{HCl}$.

\section{INTRODUCTION}

The amount of user-generated video online is increasing significantly. Using mobile devices, people can easily produce videos and share them with friends and publics via social media such as Youtube, Facebook, Twitter, Instagram, and Snapchat. Particularly, studies show that people are attracted to capturing and broadcasting their experiences in public events such as concerts, festivals, and sports games $[4,10]$.

Simultaneously with the rapid proliferation of user-generated video content, we have witnessed a shift in public library development. While libraries have traditionally focused on provision of knowledge (i.e., via their collection of books), public libraries these days are becoming a 'third place' for co-creation of knowledge with local community members [9]. Notable trends in this shift include digital placemaking and activity support in libraries [1,6]. Public libraries are now hosting a variety of cultural events and community activities, ranging from large scale exhibitions to weekly local meet-up groups. While these activities are often highly valued by library patrons, there are no dedicated services to capture the knowledge generated during these activities, meaning that once an activity is over, the insights and materials that might have been created during the activity are easily lost.

We work on a cross-European research project called PLACED (http://placedproject.eu/), in which we aim to develop digital services that support knowledge co-creation by the local community members as they actively participate in a range of library activities. In particular, we are interested in exploring the role of user-generated video as a means to document and disseminate local knowledge. In this paper, we therefore explore the question: What are the potentials and challenges for supporting and leveraging user-generated video content in library activities?

\section{BACKGROUND}

Using video as a medium for knowledge production in public libraries is not new. Consider, for example, Tucson Public Library's video program in the 80 s, in which librarians were sent out to produce video cassettes about the history, peoples, and cultures of the Sonoran Desert where Tucson is located [5]. More recent research has looked into the relationships between marketing on social media and user engagement in public libraries (e.g., [7]) and the potential for streaming video lending services (e.g., [8]). However, most of the existing work has focused on supporting the traditional role of public libraries as repositories of knowledge. Little work has been done to support their emergent role as urban cultural hubs for participatory local knowledge production and dissemination. For the past 


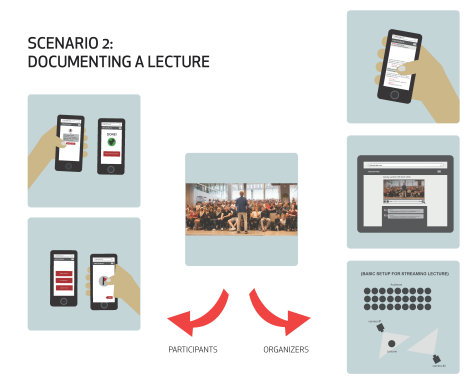

Figure 3: Scenario 2 - The event organizers set up two cameras: One focusing on the speaker/slides and another one with a wider view of the audience. An algorithm will cut between these two cameras while live-streaming the video, increasing real time access into the activity. In order to highlight the most interesting parts of the lecture, event participants can create a short video markup with their mobile devices, adding comments on the video timeline. People who are not able to attend can also highlight interesting parts while watching the lecture from any place with an internet connection in any device available. years, we have worked in a cross-European project aiming to develop place- and activity-centric digital library services [6,9], which can support this emergent role of libraries.

\section{METHOD}

In order to explore the need and possibility for using user-generated videos in public library settings, we conducted focus groups with a total of six library staff from two public libraries, one in Denmark (hereinafter referred to as PL1) and one in Sweden (hereinafter referred to as PL2) (see Figure 1 for details). Specifically, we conducted a semi-structured group interview with three library staff from each location. In addition, we conducted a follow-up interview with one of the library staff in PL1. In this follow-up interview, we used design scenarios as probes to explore specific issues raised during the feedback sessions on an early prototype of the place- and activity-centric digital library service [6] (see Figure 2, 3, and 4). The interviews were transcribed and imported into NVivo 11 for thematic analysis [2]. The themes were further analyzed and categorized into design potentials and challenges.

In the following sections, we share preliminary insights from our data analysis with illustrative quotes from the participants' responses. First, we present four key potentials for using user-generated videos to advance library services. Next, we discuss five key challenges that need to be considered.

\section{POTENTIALS}

Giving Voice. In both libraries, participants saw value in broadcasting patron-generated videos either on public displays in the library or on social media in general. Importantly, patron-generated videos can serve as a powerful tool for giving voice to community members to express their own experiences of being in the library.

D1: "If we had the right to do it, to share it [patron-generated videos], yeah that would be great. I mean we always look for good content to show what's going on here and how do people experience being here. That's why we like to use Instagram, because that [Instagram] is what we have right now, but that [patron-generated video] shows the experience of being at [PL1] from a point of view which is not ours. And I think that has a lot of value for us. Because this is not us saying something about the place, it's the people using the place saying something about their experience here. And that's the most valuable communication."

Cultivating Ownership. Interestingly, participants felt that de-anonymization (i.e., giving credit to individual creators) might lead to increased sense of ownership not only of a particular video made by the patron but also of the library collection as a whole.

D1: "Because we would like people to feel ownership for this alignment [attaching their personal identity to the video that they have generated]. And when you feel ownership, you won't harm the place, you will protect it. So that is what we are aiming for." 


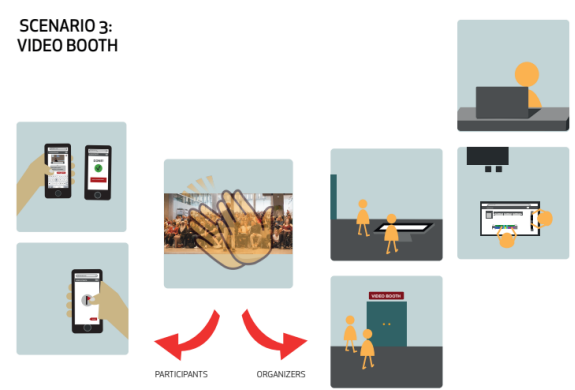

Figure 4: Scenario 3 - The library has a video booth. Patrons and librarians who want to edit the video can collaborate inside this space. Only those who come to the video booth can edit the videos, thus preventing random outsiders from manipulating the content.
Participants expected that by claiming their individual identity, patrons will become more responsible for what they produce and take pride in what they personally contribute to the community.

Increasing Accessibility. Consistent with the findings from the previous study [9], participants emphasized the need for providing better access to make sure that everyone is invited to partake in library activities. Participants thought that patron-generated videos such as live-streamed videos might allow other patrons, who are unable to physically attend library activities (e.g., disabled citizens, citizens living in rural areas), to participate remotely. Participants also saw value in making videos of the past events available online so that patrons would have the opportunity to go back and review them (e.g., if there were something that they missed or did not understand during the activity).

L1: "Author visits or a lecture or something we could record and then save it for later, for people who are not here."

L2: "Or maybe [people] would go to a lecture or author visits and when they come home they want to watch some parts again-that could have a value."

Improving Evaluation Practice. Finally, we asked the participants how videos might be used to improve their evaluation practices, for example, for their annual report. We asked this question based on the librarians' need identified in the previous study [9]. At first, participants indicated that they were not sure how the kinds of videos discussed in the interview (i.e., patron-generated videos) could assist in gathering statistics for the report (e.g., how can you count the number of attendees by analyzing videos?). However, they were convinced that videos could be useful for monitoring and evaluating their personal performances during the events.

\section{CHALLENGES}

Privacy Regulations. Participants raised practical concerns surrounding the General Data Protection Regulation (GDPR), a regulation on data protection and privacy for all individuals within the European Union (EU) and the European Economic Area (EEA) [3]. At PL1, they currently have public displays that show random Instagram photos with the library hashtag. When asked about the possibility to use patron-generated videos documented via official library services instead of Instagram photos, participants became concerned that patrons may not understand the legal implications of the GDPR. D1 emphasized the importance and the difficulty of obtaining informed consent to ensure that people are not recorded unknowingly or against their wishes.

D1: "What if I'm a homeless guy sleeping on the computer downstairs, and somebody records it, and it's on the screen? I don't have a phone or I don't know how to access this platform and anonymize my face."

Participants from PL2 were also deeply concerned, especially because children are their primary target group for workshop activities (e.g., makerspace, creative workshops). In order to produce videos, 


\section{FOUR DESIGN POTENTIALS}

\section{P1. Giving Voice}

User-generated videos can serve as powerful tools for giving voice to community members to express their own experiences of being in the library.

\section{P2. Cultivating Ownership}

Giving credit to individual creators contributing videos can lead to an increased sense of ownership of the library collection as a whole.

\section{P3. Increasing Accessibility}

User-generated videos can serve as fruitful tools for allowing more people to participate in library activities both physically and remotely.

\section{P4. Improving Evaluation Practice}

User-generated videos can be useful for monitoring and evaluating librarians' personal performances during organized activities. the library would need to collect informed consent from the children and written assent from their guardians unless they only record unidentifiable information (e.g., the hands of children).

Anonymization and Abuse. While deeply concerned with privacy regulation, participants were also against the idea of allowing anonymous contributions in fear of potential vandalism and trolling.

D1: "And we all know how people behave in anonymous ways on social media. [...] The tendency goes towards being more rude, more brutal, and I don't know if that would happen in this way. I think we would have to experiment with that [the effect of anonymization]. We've seen a tendency towards that in the digital domain, and it would be interesting to see because it's hard to say right now."

Sense of Expertise. While people frequently share videos on social media for casual purposes, participants pointed out that patrons may feel reluctant to share videos to become a part of the library collection, where videos are seen as a representation of knowledge. Participants from PL1 explained that many patrons do not consider themselves experts, i.e., compared to invited authors and lecturers in many library events, therefore, seeing little value in contributing their own inexpert knowledge.

D1: "Most people like to share their knowledge if they feel strongly about it, but if you attend an event about an author and a book [...] then it is a bit more difficult to share your knowledge because you're not an expert, you are just an attendee."

Sense of Community. Interestingly, participants tied motivation for sharing with a sense of community. They imagined that patrons may be motivated to share videos based on a strong sense of community among the event participants, yet, only in smaller group settings such as a local reading group or a language cafe, where locals regularly meet and get to know each other. In contrast, at bigger events such as a public lecture full of anonymous audiences lacking a sense of community, it was deemed less likely that people will want to share their videos.

Pro-quality Video Post-production. Participants emphasized the importance of producing high quality videos. Participants from PL1 explained that the video clips they share on social media hardly receive any views, that viewers quickly lose interest if the video presents less than perfect quality (e.g., a shaky camera). Furthermore, it would be difficult to paint a cohesive picture of an any given event with so many videos generated by different patrons, each with a different look and feel. Therefore, participants emphasized the need for proper post-production editing. For example, at PL1, the library have created a nice video montage in the past, which was outsourced to a couple of journalism students. However, library staff have neither time nor the technical expertise to carry out professional editing of videos themselves. Thus, participants emphasized that patron-generated videos will be very useful if the post-production editing process could be automated somehow. 


\section{FIVE KEY CHALLENGES}

\section{C1. Privacy Regulations}

As public institutions, libraries are strictly bound by the GDPR and other municipal policies to collect, use, or process people's personal data.

\section{C2. Anonymization and Abuse}

Being open to publics, libraries can become an easy target for vandalism and trolling, especially if anonymous participation is allowed.

\section{C3. Sense of Expertise}

Patrons may not feel confident about sharing their videos to become a part of the library collection, where videos are seen as a formal representation of knowledge as opposed to an informal piece of entertainment.

\section{C4. Sense of Community}

Without a pre-established sense of community, patrons may feel reluctant to share their videos with strangers.

\section{C5. Pro-quality Video Post-production}

To be published as a library collection, usergenerated videos require high-quality postproduction from library staff who neither have time nor the technical expertise to carry out professional editing.

\section{ACKNOWLEDGMENTS}

Thanks to all who took part in this study. This work was funded by Vinnova 2017-01553, Innovation Fund Denmark 5123-00007B, Agence Nationale de la Recherche ANR-16-ENSF-0004, and JPI Urban Europe EU 693443.

\section{CONCLUSION AND FUTURE WORK}

As stated above, our overarching goal is to develop place- and activity-centric digital library services that support co-creation of local knowledge by the community members as they actively participate in a range of library events. While people are already producing videos in various public events and often sharing them online, such videos are currently fragmented across many different social media platforms. We argue that there is much value in building a common platform for documenting user-generated videos for the purpose of local knowledge production. While different from traditional expert knowledge, such videos can effectively convey the wisdom of lived experience of the local community. Public libraries can further the democratization of knowledge, not only by providing access to established knowledge via books and organized activities, but also by cultivating emergent, community-generated knowledge via videos, thus, supporting collaboration beyond participation.

\section{REFERENCES}

[1] Maija Berndtson. 2013. Public libraries and placemaking. In IFLA WLIC 2013 - Singapore - Future Libraries: Infinite Possibilities. IFLA, Singapore, 1-10. http://library.ifla.org/id/eprint/224

[2] Virginia Braun and Victoria Clarke. 2006. Using thematic analysis in psychology. Qualitative research in psychology 3, 2 (2006), 77-101.

[3] EU. 2018. General Data Protection Regulation. Retrieved Jan 5, 2019 from https://gdpr-info.eu/

[4] Michael Evans, Lianne Kerlin, Olivia Larner, and Rosie Campbell. 2018. Feels Like Being There: Viewers Describe the Quality of Experience of Festival Video Using Their Own Words. In Extended Abstracts of the 2018 CHI Conference on Human Factors in Computing Systems (CHI EA '18). ACM, New York, NY, USA, Article LBW029, 6 pages. https: //doi.org/10.1145/3170427.3188507

[5] Helen N. Gothberg. 1982. Videoworks at the Tucson public library. Library journal (January 1982).

[6] Carla Gröschel, Peter Dalsgaard, Clemens N. Klokmose, Henrik Korsgaard, Eva Eriksson, Raphaëlle Bats, Aurélien Tabard, Alix Ducros, and Sofia E. Serholt. 2018. PARTICIPATE: Capturing Knowledge in Public Library Activities. In Extended Abstracts of the 2018 CHI Conference on Human Factors in Computing Systems (CHI EA '18). ACM, New York, NY, USA, Article LBW060, 6 pages. https://doi.org/10.1145/3170427.3188605

[7] Soohyung Joo, Namjoo Choi, and Tae Hyun Baek. 2018. Library marketing via social media: The relationships between Facebook content and user engagement in public libraries. Online Information Review 42, 6 (2018), 940-955. https: //doi.org/10.1108/OIR-10-2017-0288

[8] Brandi Scardilli. 2014. Streaming Video in Public Libraries. Information Today 31, 6 (2014).

[9] Sofia Serholt, Eva Eriksson, Peter Dalsgaard, Raphaëlle Bats, and Alix Ducros. 2018. Opportunities and Challenges for Technology Development and Adoption in Public Libraries. In Proceedings of the 10th Nordic Conference on Human-Computer Interaction (NordiCHI '18). ACM, New York, NY, USA, 311-322. https://doi.org/10.1145/3240167.3240198

[10] Stefan Wilk and Wolfgang Effelsberg. 2013. Crowdsourced Evaluation of the Perceived Viewing Quality in User-generated Video. In Proceedings of the 2Nd ACM International Workshop on Crowdsourcing for Multimedia (CrowdMM '13). ACM, New York, NY, USA, 35-36. https://doi.org/10.1145/2506364.2506370 